\title{
LAPAROSCOPIC TREATMENT OF HYDATID CYST OF LIVER
}

\author{
Rajneesh Kumar1, Kulbir Kaur², Ankur Hastir ${ }^{3}$
}

${ }^{1}$ Associate Professor, Department of Surgery, Punjab Institute of Medical Sciences, Jalandhar.

${ }^{2}$ Director-Principal \& Professor, Department of Pathology, Punjab Institute of Medical Sciences, Jalandhar.

${ }^{3}$ Assistant Professor, Department of Surgery, Punjab Institute of Medical Sciences, Jalandhar.

\section{ABSTRACT}

\section{BACKGROUND}

Hydatid cyst may occur in any part of the Liver. Surgery remains the gold standard in terms of treatment of patients of hydatid cyst in liver. Laparoscopic treatment is safe in hydatid liver disease.

Objective- To evaluate the safety and feasibility of laparoscopic treatment of hydatid cyst of liver.

\section{MATERIALS AND METHODS}

The study included 30 patients who had undergone laparoscopic management of hydatid liver disease at civil hospital, Jalandhar from Nov. 2007 to Sept. 2012 and at Punjab Institute of Medical Sciences (PIMS), Jalandhar from Sept. 2012 to June 2016. Age, sex, duration of surgery, surgical morbidity, hospital stay, recurrence of disease were noted to evaluate the safety and feasibility of this procedure.

\section{RESULTS}

Laparoscopic treatment was performed on thirty patients (Eighteen males and twelve females) with conversion to open surgery necessary in one male patient due to dense intra-abdominal adhesions. Mean age was 44 years (range 18-70 years). Size ranged from 8-12 centimetres with mean diameter 9.5 centimetres. There was no disease or procedure-related mortality. Hospital stay was 2-4 days. Three patients had external biliary fistula resulting from communication between cyst and the biliary tree which healed spontaneously without intervention after 26 days, 40 days and 2 months. There were two recurrences in the one-year followup period.

\section{CONCLUSION}

Laparoscopic management of hydatid cysts of liver can be performed safely and successfully with certain precautions. Laparoscopic surgery of hepatic hydatid disease has been increasingly popular and has undergone a revolution parallel to the progress in laparoscopic surgery.(1)

\section{KEYWORDS}

Laparoscopic, Liver, Hydatid cyst.

HOW TO CITE THIS ARTICLE: Kumar R, Kaur K, Hastir A. Laparoscopic treatment of hydatid cyst of liver. J. Evolution Med. Dent. Sci. 2017;6(41):3260-3263, DOI: 10.14260/Jemds/2017/706

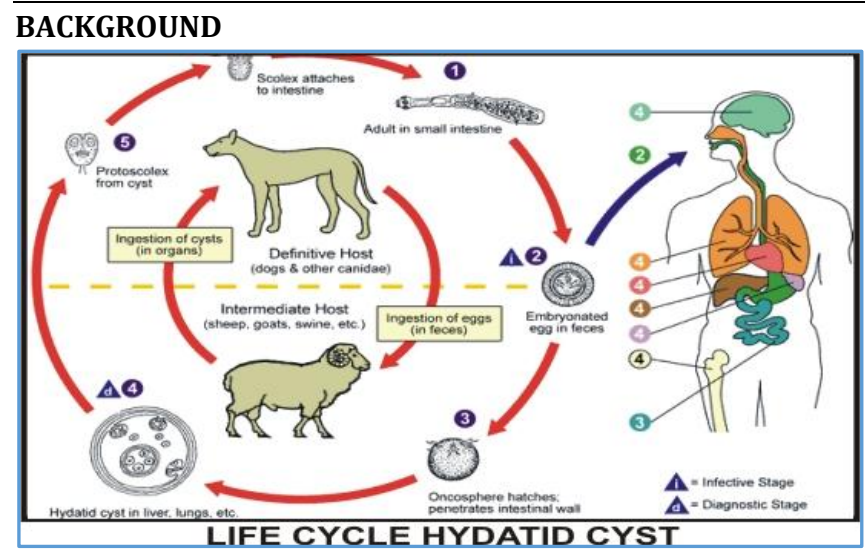

Figure 1

Financial or Other, Competing Interest: None

Submission 17-04-2017, Peer Review 12-05-2017,

Acceptance 17-05-2017, Published 22-05-2017.

Corresponding Author:

Rajneesh Kumar,

87-D, Dilbagh Nagar,

Adarsh Hospital, 120-Feet Road,

Jalandhar-144002, Punjab.

E-mail: drrajneeshkumar@ymail.com

DOI: $10.14260 /$ jemds $/ 2017 / 706$

\section{(c) ${ }_{\mathrm{BY}}(\mathrm{NC}$}

Hydatid disease is endemic mainly in the Mediterranean countries, Middle East, South America, India, Northern China, Australia and Far East and sheep raising areas.(2,3,4) Hydatid disease is a zoonotic infection caused by adult or larval stages of Echinococcus granulosus. Liver is the most commonly affected organ (75\%), followed by lungs, spleen, kidney, brain, etc. The typical lesion is a cystic cavity, filled with clear hydatid fluid containing live protoscoleces. Hydatid cyst has two layers: The ectocyst or pericyst, a dense fibrous outer layer and an inner layer called endocyst or the germinative membrane from which brood capsules containing protoscoleces proliferate towards the cystic cavity. Actually, the ectocyst consists of compressed liver cells and fibrotic tissue, which is a host reaction to the presence of the parasite and does not belong to the parasite but to the host liver. Therefore, the only live material, which should be the target of any treatment modality, is the germinative membrane and the fluid it contains together with live and infective protoscoleces or daughter cysts.

Surgery remains the gold standard treatment for patients with echinococcosis despite significant economic costs, advances in medical treatment, and interventional radiology.(5-7) The aims of surgery are complete evacuation of the cyst without spillage followed by sterilisation and obliteration of the cavity. Laparoscopic approach is a suitable surgical technique to achieve these aims. In last two decades, laparoscopic treatment of hydatid cyst of liver has become 
increasingly popular and has undergone a revaluation parallel to the progress in laparoscopic surgery.(1) Different reports of laparoscopic surgery of liver hydatid cyst exist, some are case reports ${ }^{(8-13)}$ and some are series of less than ten to fifteen cases.(14-16)

Still controversies about the role of laparoscopy in the management of liver hydatid cyst exist worldwide including technical problems in intraparenchymal cysts which do not reach surface of liver, cyst on posterior location with difficult laparoscopic access, those cysts with calcified walls, and also the patients with recurrent disease may not be suitable for laparoscopic surgery due to possibility of dense intraabdominal adhesions as well as cysts with preoperatively recognised biliary communication.

With developments in laparoscopic surgery, there have been successful attempts to treat hydatid cysts of liver with added advantage of this new technique.(17-23)

\section{MATERIALS AND METHODS}

The study included 30 patients who have undergone laparoscopic management of hydatid liver disease at civil hospital, Jalandhar from Nov. 2007 to Sept. 2012 and at Punjab Institute of Medical Sciences (PIMS), Jalandhar from Sept. 2012 to June 2016. Age, sex, duration of surgery, surgical morbidity, hospital stay, recurrence of disease were noted to evaluate the safety and feasibility of this procedure. The disease was diagnosed by abdominal ultrasonography, CT scan and confirmed by serological examination. X-ray chest done in all patients. Our inclusion criteria were- solitary cyst located in segments 3, 4, 5, 6 and 8 with diameter between 8-12 centimetres and with no evidence of calcification, preoperative biliary communication or cyst infection. Exclusion criteria were- multiple hydatid cysts or cyst located in segment 1,2 and 7 as they are the blind areas for laparoscopic procedures. Intraparenchymal location of cyst was excluded as well. There were six men and five women. The mean age was 44 years (range 18-70 years). The mean cystic diameter was 9.5 centimetre (range 8-12 centimetre). Eleven cysts were located in segment 4, eight cysts located in segment 5 , six cysts located in segment 6 and five located in segment 8. After the diagnosis, medical treatment with Albendazole $10 \mathrm{mg} / \mathrm{kg}$ (400 mg BD) per day was given for 3 weeks before surgery in all patients. We planned a laparoscopic surgical approach. Pre-operative liver function tests were normal in all the patients.

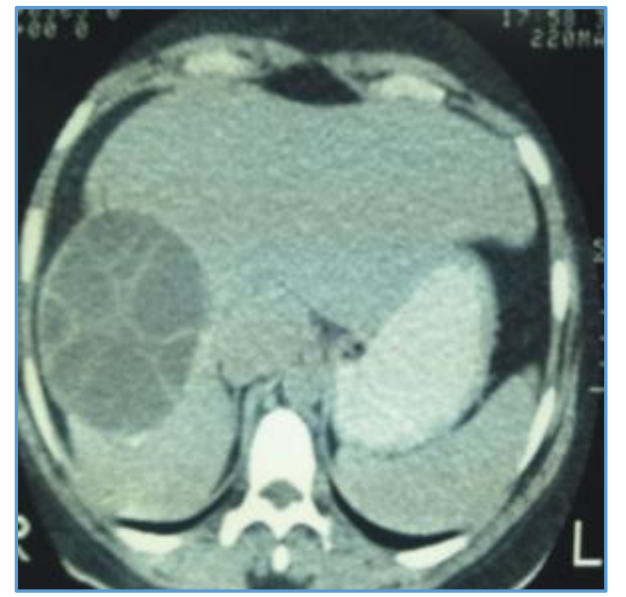

Figure 2. Computed Tomography Demonstrated a $14 \mathrm{~cm} \mathrm{x}$ $9.7 \mathrm{~cm}$ Cyst in the Right Lobe of Liver
We used three $10 \mathrm{~mm} \&$ one $5 \mathrm{~mm}$ trocars. The cyst was approached laparoscopically by using same hydatid asepsis techniques as in open surgery. Under general anaesthesia, patient was placed in supine position, surgeon and camera assistant standing on the left side of the patient with the assistant \& scrub nurse standing on right side of the patient. Using CO2 pneumoperitoneum pressure of $12 \mathrm{mmHg}$ was obtained. Diagnostic laparoscopy was performed to localise the cyst through a $10 \mathrm{~mm}$ infraumbilical port. A $10-\mathrm{mm}$ port used at the epigastrium as a working port and an additional $10 \mathrm{~mm}$ port at midclavicular right subcostal through which Palanivelu Hydatid System (PHS) was used and another $5 \mathrm{~mm}$ port on right lateral side depending on site of cyst. Roll gauzes soaked in hypertonic saline $(20 \% \mathrm{NaCl})$ placed around the cyst and an Endobag made from vacusuction with internal sterile plastic cover put into abdomen through $10 \mathrm{~mm}$ epigastric port. More hypertonic saline was injected with Veress needle over the roll gauzes which surround the cyst.

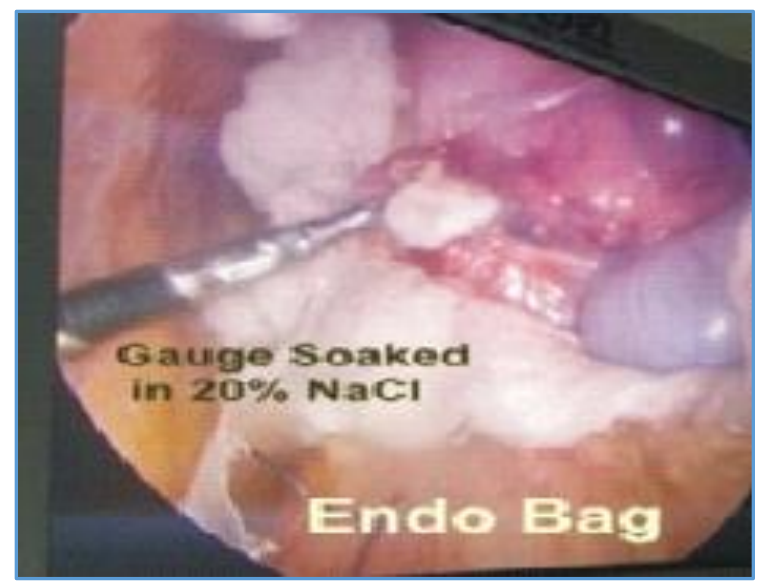

Figure 3. Roll Gauzes Soaked in Hypertonic Saline (20\% $\mathrm{NaCl}$ ) Placed Around the Cyst

Then PHS introduced directly into cyst and connected to suction for continuous vacuum suction. Irrigation of the cyst done with hypertonic saline which was allowed to remain for 15 minutes and changed 4 to 5 times. A portion of cyst wall excised for pathological examination.

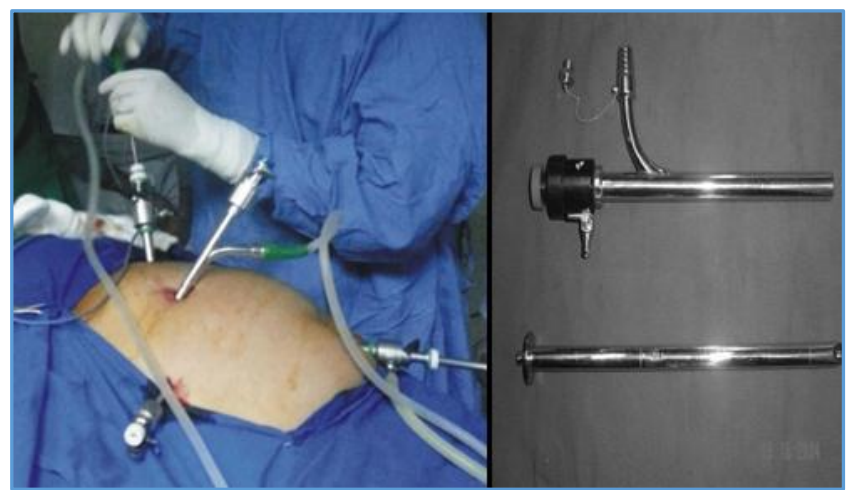

Figure 4. Using Palanivelu Hydatid System [PHS]

The germinative layer and hydatid daughter cysts were sucked out with $10 \mathrm{~mm}$ suction and removed with care and placed in Endobag (Fig. 5) and retrieved through epigastric port. Then laparoscope was inserted into cyst to exclude any biliary communication or retained daughter cysts. The cyst 
cavity was irrigated with hypertonic saline several times. Pericystectomy was performed using electrical curved scissors and a spatula. Gauze pieces were removed through $10 \mathrm{~mm}$ epigastric trocar. The pericyst cavity was obliterated with omentum after putting a suction drain into the cavity.

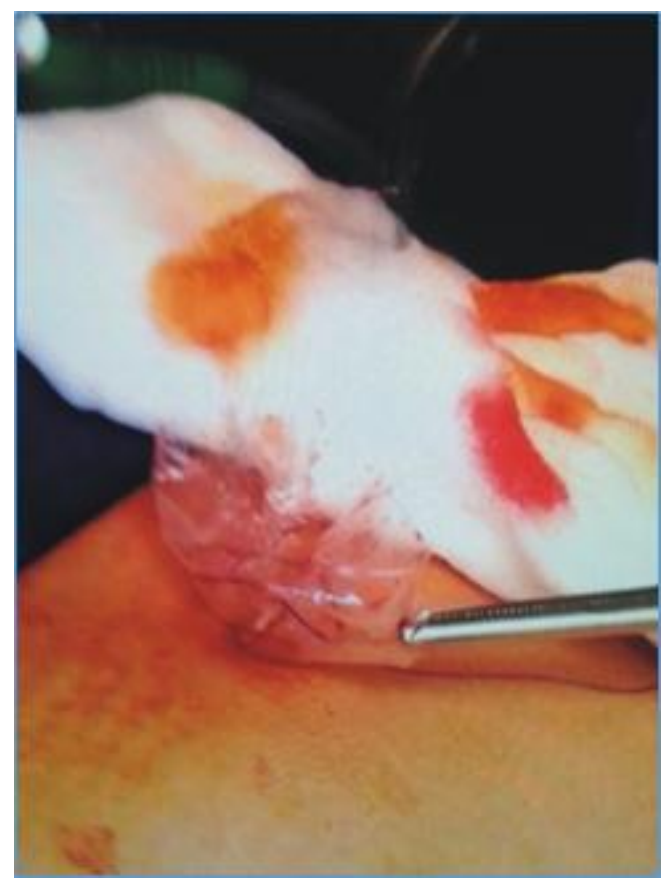

Figure 5. Extraction of Endobag with Contents

Oral liquid intake was allowed on same day of surgery after 6 hours. If no bile is draining through Romovac drain, drain is removed 48 hours post-operation. All the patients did well postoperatively and discharged on $3^{\text {rd }}$ or $4^{\text {th }}$ day. The patients were planned to be followed up at one month, three months, six months and then yearly for ultrasonography and serology.

Albendazole $10 \mathrm{mg} / \mathrm{kg}$ was started from postoperative day 1 and continued for 21 days, then a gap of 14 days given. 3 cycles recommended to prevent recurrence.

\section{RESULTS}

In all the cases diagnosis was confirmed by ultrasonography, CT scan, Serology and all the patients had normal liver function tests. Laparoscopic treatment was performed on thirty patients (eighteen males and twelve females) with conversion to open surgery necessary in one male patient due to dense intra-abdominal adhesions. There was no disease or procedure-related mortality. Hospital stay was 2-4 days. Three patients had external biliary fistula resulting from communication between cyst and the biliary tree which healed spontaneously without intervention after 26 days, 40 days and 2 months. There were two recurrences in the oneyear followup period.

To prevent recurrence all the patients were put on Albendazole $10 \mathrm{mg} / \mathrm{kg}$ started from postoperative day 1 and continued for 21 days, then a gap of 14 days given. 3 cycles were recommended.

\section{DISCUSSION}

Hydatid disease is characterised by worldwide distribution and frequent hepatic involvement.(24) In classical open surgery, overall postoperative mortality ranges between $0 \%(25)$ to as high as $7.5 \%(26)$ in the early period. Morbidity is also observed in $4-25 \%(13,16,18)$ of the cases. It is better and safe to use laparoscopic surgery in treatment of hydatid liver with less morbidity, mortality, and shorter hospital stay and recurrence rate in comparison with open technique. It also prevents intraperitoneal spillage of cyst contents.(27) Biliary communications are reportedly common in hydatid disease. (28) \& 19(29)

Laparoscopic approach offers better visual control of the cyst cavity under magnification, which allows better detection of small open bile ducts that leak bile. These can be taken care by direct suturing or cauterisation and better visualisation of the remains of germinative layer of the cyst.

The procedure is contraindicated in patients with secondary infected cysts, or suspected biliary communication (Bile-stained aspirate), owing to increased risk of complications. (30) Posterior cysts, more than three cysts, cysts with thick \& calcified walls are also contraindicated.

Inactivation of cyst with $20 \% \mathrm{NaCl}$ (hypertonic saline), removal of the cyst contents without contaminating the abdomen, followed by appropriate management of any remaining cavity. $(24,30)$ The cyst is approached laparoscopically by using same hydatid aseptic techniques as in open surgery. We have converted one laparoscopic procedure to open in one male patient due to dense adhesions. Patient selection depending on site of cyst is important in early experience as advocated by many authors.(19) Draining of remaining cyst cavity for 48 hours by Romovac drain helps to obliterate cavity and prevents biliary peritonitis if bile leak is there. We always used the technique of obliterating the cavity by plugging the greater omentum. PHS is successful in preventing spillage, evacuating the contents of hydatid cysts, performing transcystic fenestration and dealing the cyst- biliary communications. We used this suction cannula to evacuate the cyst contents. Advances in laparoscopic technology and with the introduction of harmonic scalpel resection is possible in more complicated cysts. With limitation of harmonic scalpel, we worked cautiously to avoid unnecessary risks to our patients of liver hydatid cyst.

\section{CONCLUSION}

Laparoscopic management of hydatid cysts of liver can be performed safely and successfully with certain precautions. It has been increasingly popular and has undergone a revolution parallel to the progress in laparoscopic surgery.

\section{REFERENCES}

[1] Ertem M, Karahasanoglu T, Yavuz N, et al. Laparoscopically treated liver hydatid cysts. Arch Surg 2002;137(10):1170-3.

[2] Mentes A. Hydatid liver disease: a perspective in treatment. Dig Dis 1994;12(3):150-60.

[3] Meyers WC, Kim RD, Chari RS. Echinococcal cysts. In: Townsend CM, Beauchamp RD, Evers BM, et al. eds. Sabiston textbook of surgery: the biological basis of modern surgical practice. Philadelphia: WB Saunders 2001:1053-5.

[4] Sayek I, Yalin R, Sanac Y. Surgical treatment of hydatid disease of liver. Arch Surg 1980;115(7):847-50. 
[5] Acunas B, Rozanes I, Celik I, et al. Purely cystic hydatid disease of the liver: treatment with percutaneous aspiration and injection of hypertonic saline. Radiology 1992;182(2):541-3.

[6] Todorov T, Vutova K, Mechkov G, et al. Chemotherapy of human cystic echinococcosis: comparative efficacy of mebendazole with albendazole. Ann Trop Med Parasitol 1992;86(1):59-66.

[7] Manterola C, Fernadez O, Munoz S, et al. Laparoscopic pericystectomy for liver hydatid cysts. Surg Endosc 2002;16(3):521-4.

[8] Guibert L, Gayral F. Laparoscopic pericystectomy of a liver hydatid cyst. Surg Endosc 1995;9(4):442-3.

[9] Katkhouda N, Fabiani P, Benizri E, et al. Laser resection of a liver hydatid cyst under videolaparoscopy. Br J Surg 1992;79(6):560-1.

[10] Massoud WZ. Laparoscopic excision of a single hepatic hydatid cyst. Int Surg 1996;81(1):9-13.

[11] Rogiers X, Bloechle C, Broelsch CE. Safe decompression of hepatic hydatid cyst with laparoscopic surgiport. Br J Surg 1995;82(8):1111.

[12] Mark J, Mouiel J, Katkhouda N, et al. Laparoscopic liver surgery. A report on 28 patients. Surg Endosc 1998;12(4):331-4.

[13] Saglam A. Laparoscopic treatment of a liver hydatid cyst. Surg Laparosc Endosc 1996;6(1):16-21.

[14] Yucel 0, Talu M, Unalmiser S, et al. Videolaparoscopic treatment of a liver hydatid cyst with partial cystectomy and omentoplasty: A report of two cases. Surg Endosc 1996;10(4):434-6.

[15] Khoury G, Abiad F, Geagea T, et al. Laparoscopic treatment of hydatid cysts of the liver and spleen. Surg Endosc 2000;14(3):243-5.

[16] Seven R, Berber E, Mercan S, et al. Laparoscopic treatment of hepatic hydatid cysts. Surgery 2000;128(1):36-40.

[17] Sever M, Skapin S. Laparoscopic pericystectomy of liver hydatid cyst. Surg Endosc 1995;9(10):1125-6.

[18] Alper A, Emer A, Hazar H, et al. Laparoscopic surgery of hydatid disease: initial results and early follow-up of 16 patients. World J Surg 1995;19(5):725-8.
[19] Bickel A, Eitan A. The use of a large, transparent cannula with bevelled tip, for safe laparoscopic management of hydatid cysts of liver. Surg Endosc 1995;9(12):1304-5.

[20] Alper A, Emre A, Acarli K, et al. Laparoscopic treatment of hepatic hydatid disease. J Laparoendosc Surg 1996;6(1):29-33.

[21] Khoury G, Jabbour-Khoury S, Bikhazi K. Results of laparoscopic treatment of hydatid cysts of liver. Surg Endosc 1996;10(1):57-9.

[22] Verma GR, Bose SM. Laparoscopic treatment of hepatic hydatid cyst. Surg Laparosc Endosc 1998;8:280-2.

[23] Ramachandran CS, Goel D, Arora V. Laparoscopic surgery in hepatic hydatid cysts: a technical improvement. Surg Laparosc Endosc Percutan Tech 2001;11(1):14-8.

[24] Schwartz SI. Liver. In: Schwartz SI. edr. Principles of surgery. $7^{\text {th }}$ edn. New York: McGraw-Hill International inc., 1999:1395-435.

[25] Karavias DD, Vagianos CE, Bouboulis N, et al. Improved techniques in the surgical treatment of hepatic hydatidosis. Surg Gynecol Obstet 1992;174(3):176-80.

[26] Kayabali I. Sur la chirurgei des kystes hydatiques du foie. (Surgery of hydatid cysts of the liver. 368 personal cases). Lyon Chir 1971;67(5):327-9.

[27] Bickel A, Loberant N. Laparoscopic treatment of liver hydatid cyst. Br J Surg 1994;81(4):627.

[28] Bilge A, Sozuer EM. Diagnosis and surgical treatment of hepatic hydatid disease. HPB Surg 1992;6(1):57-64.

[29] Berrada S, Essadki B, Zaerouli NO. Kyste hydatique du foie. Traitement par resection du dome saillant. Notre experience a propos d'une serie de 495 cas. Our experience of the treatment of hydatid cyst of the liver by resection of the cyst wall. Annales de Chirurgie 1993;47(6):510-12.

[30] Barnes SA, Lillemoe KD. Liver abscess and hydatid cyst disease. In: Zinner MJ. edr. Abdominal operations. $10^{\text {th }}$ edn. London: Prentice Hall International Inc., 1997:1513-45. 